Acta Crystallographica Section C

Crystal Structure

Communications

ISSN 0108-2701

Editor: George Ferguson

\title{
Proton-transfer and non-transfer in compounds of quinoline and quinaldic acid with L-tartaric acid
}

\author{
Graham Smith, Urs D. Wermuth and Jonathan M. White
}

Copyright $\odot$ International Union of Crystallography

Author(s) of this paper may load this reprint on their own web site provided that this cover page is retained. Republication of this article or its storage in electronic databases or the like is not permitted without prior permission in writing from the IUCr. 
Acta Crystallographica Section C

\section{Crystal Structure}

Communications

ISSN 0108-2701

\section{Proton-transfer and non-transfer in compounds of quinoline and quinaldic acid with L-tartaric acid}

\author{
Graham Smith, ${ }^{\mathrm{a} *}$ Urs D. Wermuth ${ }^{\mathrm{b}}$ and Jonathan M. \\ White ${ }^{\mathrm{c}}$
}

${ }^{\mathrm{a}}$ School of Physical and Chemical Sciences, Queensland University of Technology, GPO Box 2434, Brisbane, Queensland 4001, Australia, b'School of Science, Griffith University, Nathan, Queensland 4111, Australia, and ${ }^{\mathbf{C}}$ School of Chemistry,

University of Melbourne, Parkville, Victoria 3052, Australia

Correspondence e-mail: g.smith@qut.edu.au

Received 12 October 2006

Accepted 27 October 2006

Online 30 November 2006

The structures of two compounds of L-tartaric acid with quinoline, viz. the proton-transfer compound quinolinium hydrogen $(2 R, 3 R)$-tartrate monohydrate, $\mathrm{C}_{9} \mathrm{H}_{8} \mathrm{~N}^{+} \cdot \mathrm{C}_{4} \mathrm{H}_{5} \mathrm{O}_{6}{ }^{-} \cdot-$ $\mathrm{H}_{2} \mathrm{O}$, (I), and the anhydrous non-proton-transfer adduct with quinaldic acid, bis(quinolinium-2-carboxylate) $(2 R, 3 R)$-tartaric acid, $2 \mathrm{C}_{10} \mathrm{H}_{7} \mathrm{NO}_{2} \cdot \mathrm{C}_{4} \mathrm{H}_{6} \mathrm{O}_{6}$, (II), have been determined at $130 \mathrm{~K}$. Compound (I) has a three-dimensional honeycomb substructure formed from head-to-tail hydrogen-bonded hydrogen tartrate anions and water molecules. The stacks of $\pi$-bonded quinolinium cations are accommodated within the channels and are hydrogen bonded to it peripherally. Compound (II) has a two-dimensional network structure based on pseudo-centrosymmetric head-to-tail hydrogenbonded cyclic dimers comprising zwitterionic quinaldic acid species which are interlinked by tartaric acid molecules.

\section{Comment}

Tartaric acid is a relatively strong diprotic chiral $\alpha$-hydroxy acid $\left(\mathrm{p} K_{a 1}=2.93\right.$ and $\left.\mathrm{p} K_{a 2}=4.23\right)$ and, therefore, is potentially capable of forming both 1:1 and 1:2 proton-transfer salts with most Lewis bases. However, with stoichiometric control it is possible to selectively form 1:1 hydrogen tartrates, and the crystal structures of a large number of these 1:1 salts have been reported, particularly since these compounds usually have good crystal morphology, allowing structure determination by single-crystal X-ray analysis, which is often not possible with the parent Lewis base. Applications have been with drugs such as epinephrine (Carlström, 1973), dextromoramide (Bye, 1975), amosulalol (Furuya et al., 1989), alprenolol (Główka \& Codding, 1989), phendimetrazine (Glaser et al., 1994) and tolterodine (Košutić-Hulita \& Žegarac, 2005), as well as natural products such as alkaloids, e.g. strychnine (Gould et al., 1987), brucine (Smith, Wermuth \& White, 2006), quinine (Ryttersgaard \& Larsen, 2004), cinchonine (Puliti et al., 2001), cinchonidine (Ryttersgaard \& Larsen, 2003; Zhang et al., 2003) and quincoridine (Kania et al., 2004), and amino acids, e.g. L-alanine (Rajagopal et al., 2002), L-proline (Subha Nandhini et al., 2001), D-, L- and DLhistidine (Marchewska et al., 2003; Rajagopal et al., 2003; Johnson \& Feeder, 2004a,b,c), and L-lysine (Debrus et al., 2005).<smiles>c1ccc2[nH+]cccc2c1</smiles><smiles>O=C([O-])[C@H](O)[C@@H](O)C(=O)O</smiles>

(I)<smiles>CC(=O)c1ccc2ccccc2[nH+]1</smiles><smiles>O=C(O)[C@H](O)[C@@H](O)C(=O)O</smiles>

(II)

Because of the ready availability of $\mathrm{L}-(+)$-tartaric acid, which has the confirmed $2 R, 3 R$ absolute configuration, it has been very useful for both resolution and the crystallographic determination of absolute configuration in chiral molecular species, e.g. with the anticholinergic agent $R$-(-)-1,1-diphenyl3-piperidinobutan-1-ol (Schjelderup et al., 1990). More recently, its utility as an agent for the introduction of chirality in achiral organic compounds for the generation of crystalline materials with potentially useful non-linear optical properties has been explored (Aakeröy et al., 1992; Fuller et al., 1995; Marchewska et al., 2003; Debrus et al., 2005; Manivannan et al., 2006).

We have found that 1:1 stoichiometric interactions of the relatively strong carboxylic acids 5-sulfosalicylic acid (5-SSA) (Smith et al., 2004) and 3,5-dinitrosalicylic acid (DNSA) (Smith, Wermuth, Healy \& White, 2006) with a series of bicyclic heteroaromatic amines, including quinoline, tetrahydroquinoline, 8-hydroxyquinoline, 8-aminoquinoline and

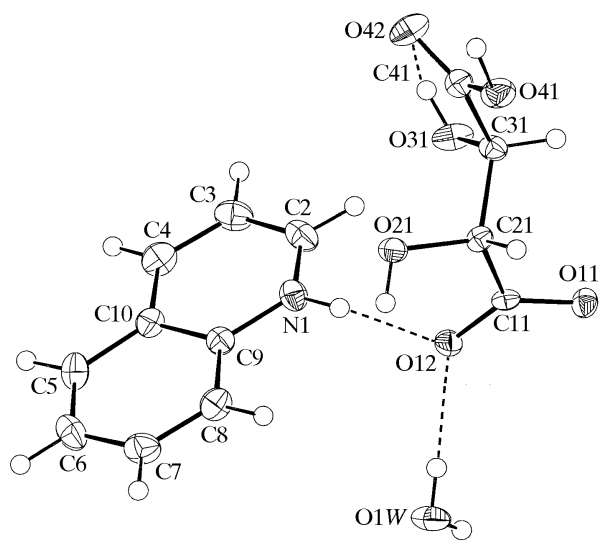

Figure 1

The molecular configuration and atom-numbering scheme for the quinolinium cation, the hydrogen L-tartrate anion and the solvent water molecule in (I). Non- $\mathrm{H}$ atoms are shown as $50 \%$ probability displacement ellipsoids. 
quinaldic acid (quinoline-2-carboxylic acid, QA), mostly gave 1:1 proton-transfer compounds. The only exception was with quinaldic acid and 5-SSA, where an adduct salt compound $\left[\mathrm{QA}^{+} \cdot 5-\mathrm{SSA}^{-} \cdot \mathrm{QA}\right]$ was found. In this structure, an unusual head-to-tail hydrogen-bonded cyclic homodimer was present [graph set $R_{2}^{2}(10)$; Etter, 1991] involving two QA species, one protonated and the other zwitterionic. With quinaldic acid itself, the crystal structure (Dobrzyńska \& Jerzykiewicz, 2004) showed the presence of a tautomeric mixture of both zwitterionic and normal acid molecules, with the zwitterions forming a similar homodimer. This was not the case with DNSA, where a conventional 1:1 product was formed with the QA molecule fully protonated.
The 1:1 reaction of these heteroaromatic amines with L-tartaric acid might be expected to give similar quinolinium hydrogen L-tartrates. Although the structures of the 1:1 tartrate salts of the previously mentioned quinine alkaloids are known (Puliti et al., 2001; Zhang et al., 2003; Ryttersgaard \& Larsen, 2003, 2004; Kania et al., 2004), those with the simple analogues of quinoline are not common. The only other tartrates of simple polycyclic heteroaromatic amines are those with benzimidazole (proton-transfer) (Aakeröy \& Hitchcock, 1994) and the non-proton-transfer $1: 1$ adduct with 1,10phenanthroline (Wang et al., 2006). Our 1:1 stoichiometric reaction of L-tartaric acid with quinoline $\left(\mathrm{p} K_{a}=4.81\right)$ resulted in the isolation of the expected proton-transfer compound, a

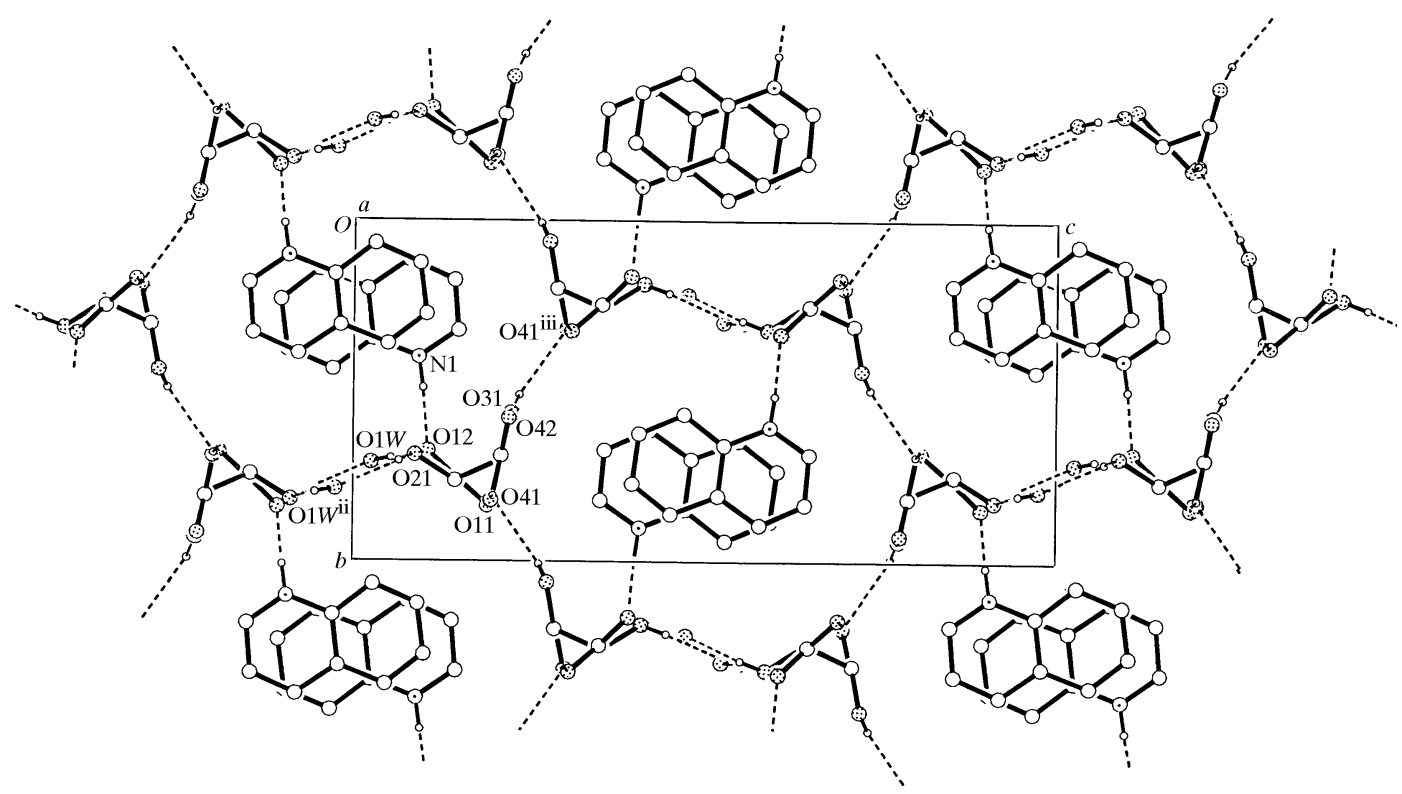

Figure 2

The packing of (I) in the unit cell, viewed down the $b$ axial direction, showing the columns of $\pi$-stacked quinolinium cations inside the tartrate-water honeycomb substructure. Hydrogen-bonding interactions are shown as broken lines and non-interactive H atoms have been omitted. (For symmetry codes, see Table 1.)

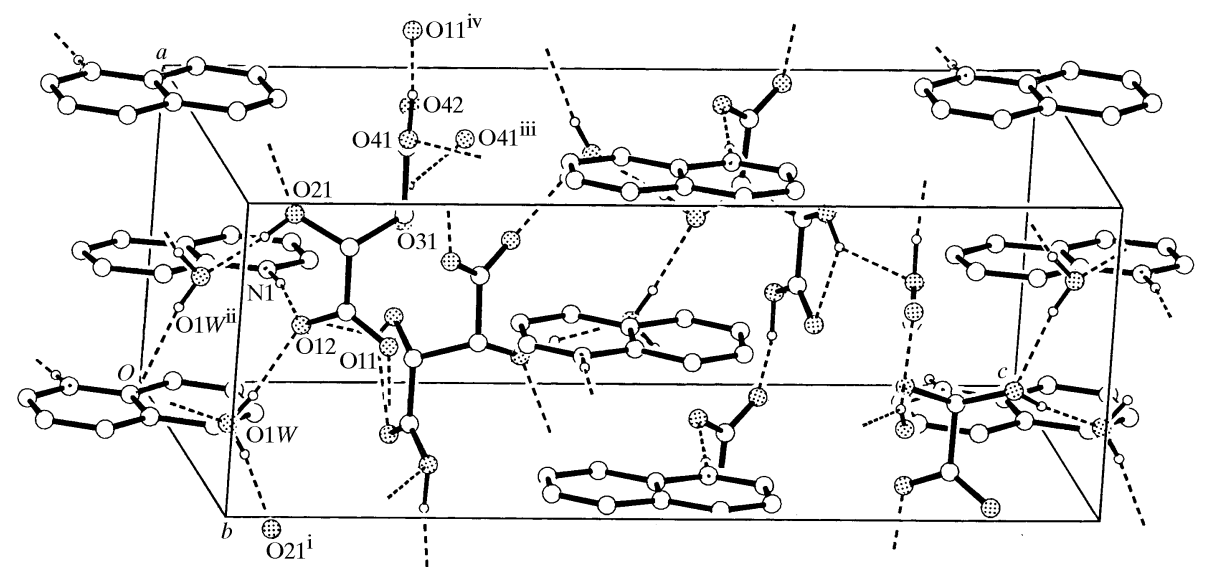

Figure 3

The packing of (I) in the unit cell, viewed approximately perpendicular to the honeycomb substructure. Hydrogen-bonding interactions are shown as broken lines and non-interactive $\mathrm{H}$ atoms have been omitted. (For symmetry codes, see Table 1.) 


\section{organic compounds}

1:1 hydrate, quinolinium hydrogen $(2 R, 3 R)$-tartrate monohydrate, (I). However, with quinaldic acid, the adduct quinolinium-2-carboxylate-(2R,3R)-tartaric acid (2/1), (II), was formed. This compound differs from the 5-SSA-QA compound by the absence of proton transfer, the two QA molecules being zwitterionic. The structures of both (I) and (II) are reported here. With the quinoline analogues 8-hydroxyquinoline and 8-aminoquinoline, the non-crystalline products obtained with L-tartaric acid did not allow a full

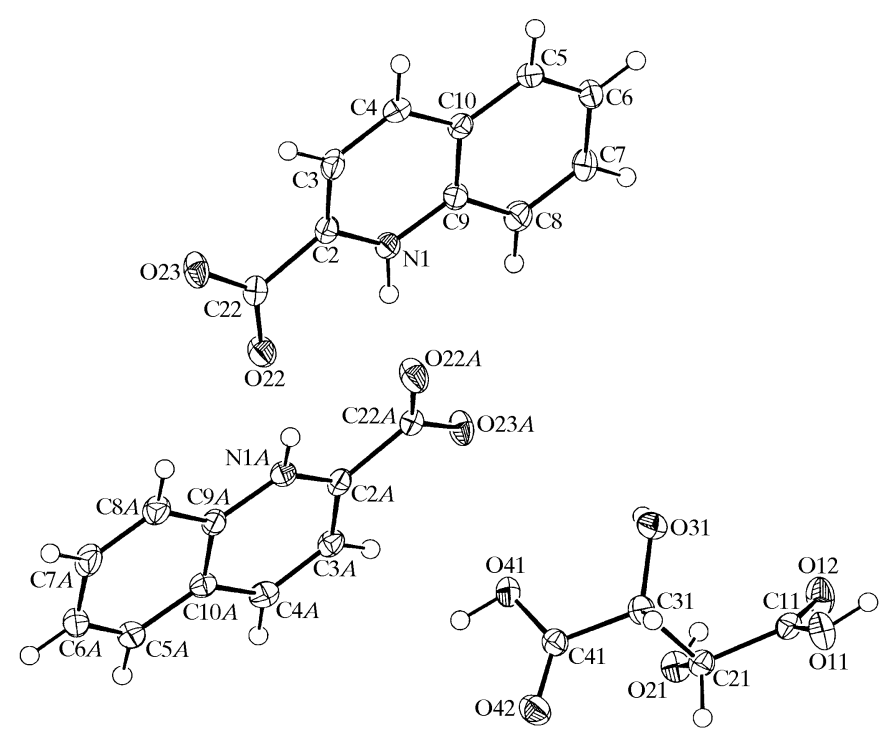

Figure 4

The molecular configuration and atom-numbering scheme for the two independent quinaldic acid zwitterions and the L-tartaric acid molecule in the asymmetric unit in (II). Non-H atoms are shown as $50 \%$ probability displacement ellipsoids. series structural comparison to be made with the quinoline salts of DNSA and 5-SSA.

Compound (I) shows the presence of single-proton transfer from L-tartaric acid to the $\mathrm{N}$ atom of quinoline (Fig. 1). The hydrogen tartrate anions and the water molecules of solvation then form an unusual three-dimensional hydrogen-bonded honeycomb substructure through carboxylate interactions with other tartrate carboxylic acid and hydroxyl groups, as well as with the water molecule (Table 1). This structure extends down the $a$ cell direction and accommodates the columns of $\pi$-stacked quinolinium cations within the channels (Figs. 2 and 3). The ring centroid separations for the alternating six-membered (N1/C2-C4/C10/C9 and C5-C10) ring systems of the quinolinium ions within the stacks are 3.7555 (11) and 3.7591 (11) $\AA$, with an inter-ring dihedral angle of $4.22(1)^{\circ}$. The cation stacks are peripherally hydrogen bonded to a carboxylate $\mathrm{O}$-atom acceptor within the substructure through a single strong link $\left[\mathrm{N}^{+}-\mathrm{H} \cdots \mathrm{O} 12=\right.$ $2.6635(18) \AA]$. Only two weak aromatic $\mathrm{C}-\mathrm{H} \cdots \mathrm{O}$ interactions are present in the structure, which in most respects is similar to that reported for the compound of L-tartaric acid with 1,10-phenanthroline (Wang et al., 2006).

With compound (II) (Fig. 4), surprisingly, no proton transfer has occurred. The two QA species are zwitterionic, forming a pseudo-centrosymmetric head-to-tail hydrogen-bonded cyclic dimer similar to that found in the structure of the acid itself (Dobrzyńska \& Jerzykiewicz, 2004). These $R_{2}^{2}(10)$ dimers are essentially planar [the torsion angles are $\mathrm{N} 1-\mathrm{C} 2-\mathrm{C} 22-$ $\mathrm{O} 22=5.4(3)^{\circ}$ and $\left.\mathrm{N} 1 A-\mathrm{C} 2 A-\mathrm{C} 22 A-\mathrm{O} 22 A=4.1(3)^{\circ}\right]$, and are stabilized by both inter- and intramolecular $\mathrm{N}^{+}-\mathrm{H} \cdots \mathrm{O}$ interactions $[\mathrm{N} 1 \cdots \mathrm{O} 22 A=2.747(3) \AA, \mathrm{N} 1 A \cdots \mathrm{O} 22=$ $2.784(3) \AA, \mathrm{N} 1 \cdots \mathrm{O} 22=2.686(3) \AA$ and $\mathrm{N} 1 A \cdots \mathrm{O} 22 A=$ 2.668 (3) ^; Table 2], as well as longer aromatic $\mathrm{C}-\mathrm{H} \cdots \mathrm{O}$

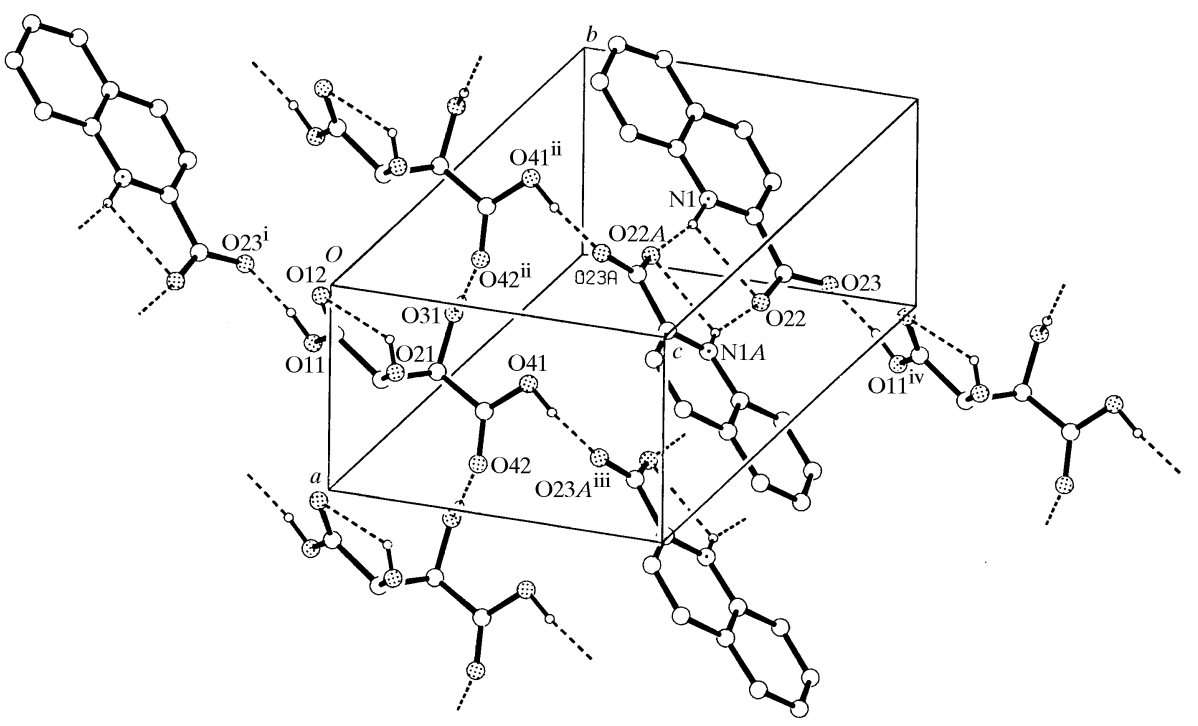

Figure 5

A perspective view of the partial packing of (II) in the unit cell, showing the zwitterionic dimer units and their extension via the tartaric acid molecules. Hydrogen-bonding interactions are shown as broken lines and non-interactive $\mathrm{H}$ atoms have been omitted. [Symmetry code: (iv) $x+1, y+1, z+1$; for other symmetry codes, see Table 2.] 


\section{organic compounds}

interactions $[\mathrm{C} 8-\mathrm{H} 8 \cdots \mathrm{O} 22 A=3.181(3) \AA$ and $\mathrm{C} 8 A-$ $\mathrm{H} 8 A \cdots \mathrm{O} 22=3.202(3) \AA]$. This is also similar to the dimers found in the $\left[\mathrm{QAH}^{+} \cdot 5-\mathrm{SSA}^{-} \cdot \mathrm{QA}\right]$ adduct, except that in this structure one of the QA species is fully protonated (Smith et al., 2004). It is therefore assumed that the absence of proton transfer in (II) is because of the stability of this zwitterionic dimer despite the $\mathrm{p} K_{a}$ difference for QA $\left(\mathrm{p} K_{a 1}=4.96\right.$ and $\left.\mathrm{p} K_{a 2}=9.02\right)$ versus tartaric acid. In (II), these dimers are linked through the tartaric acid molecules by head-to-tail heteromolecular carboxylic acid-carboxyl interactions (Table 2) which, together with homomolecular hydroxylcarboxyl extensions, give a two-dimensional network structure (Fig. 5). Contrasting with the structure of (I) there are also numerous aromatic $\mathrm{C}-\mathrm{H} \cdots \mathrm{O}$ associations with an absence of any $\pi-\pi$ interactions between the QA molecules.

The accepted $2 R, 3 R$ absolute configuration for the L-tartrate residues in both (I) and (II) (Waser, 1949; Bijvoet et al., 1951; Hope \& de la Camp, 1972) was assumed and in both compounds these adopt the common extended conformation, which is similar to those of the parent tartaric acid (Stern \& Beevers, 1950; Okaya et al., 1966; Albertsson et al., 1979), the L-acid in the anhydrous DL-acid (Luner et al., 2002) (Table 3) and the 1:1 compound with 1,10-phenanthroline (Wang et al., 2006). However, unlike these, in both (I) and (II), a single hydroxyl-carboxyl intramolecular hydrogen bond is present $[\mathrm{O}-\mathrm{H} \cdots \mathrm{O}=2.6652$ (17) and 2.639 (3) $\AA$, respectively].

While the absence of proton transfer in (II) may be explained in terms of the presence of the QA zwitterion dimer, the absence of transfer in the L-tartaric acid-1,10-phenanthroline compound reported by Wang et al. (2006) when compared with the structurally similar (I) is not understood, considering that the $\mathrm{p} K_{a}$ value for 1,10-phenanthroline (4.86) is very close to that of quinoline (4.81).

\section{Experimental}

Both compounds were synthesized by heating $1 \mathrm{mmol}$ quantities of L-tartaric acid and either quinoline [for (I)] or quinoline-2-carboxylic acid (quinaldic acid) [for (II)] in 50\% 2-propanol-water for $10 \mathrm{~min}$ under reflux. Compound (I) was obtained as colourless needles (m.p. 397.6-398.6 K) and (II) as pale-yellow plates (m.p. 469.1-470.7 K), after partial room-temperature evaporation of the solvent.

\section{Compound (I)}

\section{Crystal data}

$\mathrm{C}_{9} \mathrm{H}_{8} \mathrm{~N}^{+} \cdot \mathrm{C}_{4} \mathrm{H}_{5} \mathrm{O}_{6}{ }^{-} \cdot \mathrm{H}_{2} \mathrm{O}$
$M_{r}=297.26$
Orthorhombic, $P 2_{1} 2_{1} 2_{1}$
$a=7.2546(6) \AA$
$b=9.4922(8) \AA$
$c=19.4571(16) \AA$
$V=1339.86(19) \AA^{3}$
Data collection
Bruker SMART CCD area-detector
$\quad$ diffractometer
$\varphi$ and $\omega$ scans
Absorption correction: multi-scan
$\quad(S A D A B S ;$ Bruker, 1999$)$
$\quad T_{\text {min }}=0.88, T_{\text {max }}=1.00$

Refinement

Refinement on $F^{2}$

$w R\left(F^{2}\right)=0.088$

$S=1.04$

1795 reflections

214 parameters

$\mathrm{H}$ atoms treated by a mixture of independent and constrained refinement
$R\left[F^{2}>2 \sigma\left(F^{2}\right)\right]=0.035$

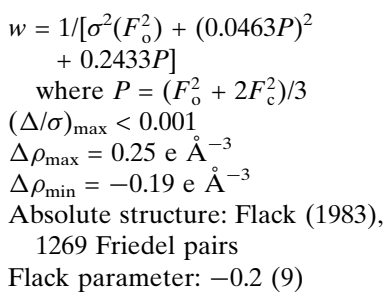

Table 1

Hydrogen-bond geometry $\left(\AA,^{\circ}\right)$ for $(\mathrm{I})$.

\begin{tabular}{|c|c|c|c|c|}
\hline$D-\mathrm{H} \cdots A$ & $D-\mathrm{H}$ & $\mathrm{H} \cdots A$ & $D \cdots A$ & $D-\mathrm{H} \cdots A$ \\
\hline $\mathrm{N} 1-\mathrm{H} 1 \cdots \mathrm{O} 12$ & 0.880 (19) & $1.797(19)$ & $2.6635(18)$ & $168(2)$ \\
\hline $\mathrm{O} 1 W-\mathrm{H} 1 W \cdots \mathrm{O} 12$ & $0.82(2)$ & $1.88(2)$ & $2.6888(17)$ & $171(2)$ \\
\hline $\mathrm{O} 1 W-\mathrm{H} 2 W \cdots \mathrm{O} 21^{\mathrm{i}}$ & $0.84(3)$ & $1.95(3)$ & $2.7832(17)$ & $170(3)$ \\
\hline $\mathrm{O} 21-\mathrm{H} 21 \cdots \mathrm{O} 1 W^{\mathrm{ii}}$ & $0.86(3)$ & $1.81(3)$ & $2.6665(17)$ & $172(3)$ \\
\hline $\mathrm{O} 31-\mathrm{H} 31 \cdots \mathrm{O} 42$ & $0.84(2)$ & $2.17(2)$ & $2.6652(17)$ & $117.7(17)$ \\
\hline $\mathrm{O} 31-\mathrm{H} 31 \cdots \mathrm{O} 41^{\mathrm{iii}}$ & $0.84(2)$ & $2.28(2)$ & $2.9480(17)$ & $136.4(19)$ \\
\hline $\mathrm{O} 41-\mathrm{H} 41 \cdots \mathrm{O} 11^{\mathrm{iv}}$ & $0.90(3)$ & $1.61(3)$ & $2.5090(16)$ & $180(4)$ \\
\hline
\end{tabular}

Symmetry codes: (i) $x-1, y, z$; (ii) $x+\frac{1}{2},-y+\frac{3}{2},-z$; (iii) $-x+2, y-\frac{1}{2},-z+\frac{1}{2}$; (iv) $x+1, y, z$.

\section{Compound (II)}

Crystal data

$\begin{array}{ll}2 \mathrm{C}_{10} \mathrm{H}_{7} \mathrm{NO}_{2} \cdot \mathrm{C}_{4} \mathrm{H}_{6} \mathrm{O}_{6} & V=556.2(3) \AA^{3} \\ M_{r}=496.42 & Z=1 \\ \text { Triclinic, } P 1 & D_{x}=1.482 \mathrm{Mg} \mathrm{m}^{-3} \\ a=4.9730(12) \AA & \text { Mo } K \alpha \text { radiation } \\ b=10.446(3) \AA & \mu=0.12 \mathrm{~mm}^{-1} \\ c=11.655(4) \AA & T=130(2) \mathrm{K} \\ \alpha=100.950(5)^{\circ} & \text { Block cut from a plate, yellow } \\ \beta=98.903(6)^{\circ} & 0.50 \times 0.40 \times 0.30 \mathrm{~mm}\end{array}$

$\gamma=106.388(5)$

Data collection

Bruker SMART CCD area-detector diffractometer

$\varphi$ and $\omega$ scans

Absorption correction: multi-scan (SADABS; Bruker, 1999)

$T_{\min }=0.95, T_{\max }=0.97$

Refinement

Refinement on $F^{2}$

$R\left[F^{2}>2 \sigma\left(F^{2}\right)\right]=0.042$

$w R\left(F^{2}\right)=0.105$

$S=1.06$

2517 reflections

321 parameters

$\mathrm{H}$ atoms treated by a mixture of independent and constrained refinement

3500 measured reflection 2517 independent reflections 2481 reflections with $I>2 \sigma(I)$

$R_{\text {int }}=0.012$

$\theta_{\text {max }}=27.3$

$$
\begin{aligned}
& w=1 /\left[\sigma^{2}\left(F_{\mathrm{o}}^{2}\right)+(0.0695 P)^{2}\right. \\
& +0.0367 P] \\
& \text { where } P=\left(F_{\mathrm{o}}^{2}+2 F_{\mathrm{c}}^{2}\right) / 3 \\
& (\Delta / \sigma)_{\max }<0.001 \\
& \Delta \rho_{\max }=0.17{\mathrm{e} \AA^{-3}}^{-3} \\
& \Delta \rho_{\min }=-0.26{\mathrm{e} \AA^{-3}}^{-3} \\
& \text { Absolute structure: Flack (1983), } \\
& 307 \text { Friedel pairs } \\
& \text { Flack parameter: }-0.4 \text { (6) }
\end{aligned}
$$

Table 2

Hydrogen-bond geometry $\left(\AA{ }^{\circ}\right)$ for (II).

\begin{tabular}{lllll}
\hline$D-\mathrm{H} \cdots A$ & $D-\mathrm{H}$ & $\mathrm{H} \cdots A$ & $D \cdots A$ & $D-\mathrm{H} \cdots A$ \\
\hline $\mathrm{N} 1-\mathrm{H} 1 \cdots \mathrm{O} 22$ & 0.92 & 2.36 & $2.686(3)$ & 101 \\
$\mathrm{~N} 1-\mathrm{H} 1 \cdots \mathrm{O} 22 A$ & 0.92 & 1.85 & $2.747(3)$ & 164 \\
$\mathrm{~N} 1 A-\mathrm{H} 1 A \cdots \mathrm{O} 22$ & 0.81 & 2.01 & $2.784(3)$ & 159 \\
$\mathrm{~N} 1 A-\mathrm{H} 1 A \cdots \mathrm{O} 22 A$ & 0.81 & 2.30 & $2.668(3)$ & 108 \\
$\mathrm{O} 11-\mathrm{H} 11 \cdots \mathrm{O} 23^{\mathrm{i}}$ & 0.89 & 1.64 & $2.521(3)$ & 168 \\
$\mathrm{O} 21-\mathrm{H} 21 \cdots \mathrm{O} 12$ & 0.79 & 2.21 & $2.639(3)$ & 115 \\
$\mathrm{O} 31-\mathrm{H} 31 \cdots \mathrm{O} 42^{\text {ii }}$ & 0.82 & 1.92 & $2.739(3)$ & 172 \\
$\mathrm{O} 41-\mathrm{H} 41 \cdots \mathrm{O} 23 A^{\text {iii }}$ & 0.92 & 1.65 & $2.557(3)$ & 173 \\
\hline
\end{tabular}

Symmetry codes: (i) $x-1, y-1, z-1$; (ii) $x-1, y, z$; (iii) $x+1, y, z$. 


\section{organic compounds}

Table 3

Selected torsion angles $\left({ }^{\circ}\right)$ within the tartrate residues of (I) and (II) compared with D-tartaric acid (D-TART) (Okaya et al., 1966), DL-tartaric acid (DL-TART) (Luner et al., 2002) and the 1,10phenanthroline-L-tartaric compound (PHENTART) (Wang et al., 2006).

\begin{tabular}{lcccrr}
\hline & (I) & (II) & D-TART & DL-TART & PHENTART \\
\hline C11-C21-C31-C41 & $174.41(12)$ & $170.9(2)$ & $175.6(16)$ & $177.6(1)$ & $174.3(3)$ \\
O11-C11-C21-O21 & $-170.33(12)$ & $-170.93(19)$ & $174.5(16)$ & $-170.3(1)$ & $-177.2(3)$ \\
O21-C21-C31-O31 & $-70.63(1$ & $-75.5(2)$ & $58(2)$ & $-65.2(1)$ & $-64.1(4)$ \\
O31-C31-C41-O41 & $178.61(12)$ & $-169.6(2)$ & $177.6(17)$ & $-170.3(1)$ & $179.6(3)$ \\
\hline
\end{tabular}

$\mathrm{H}$ atoms potentially involved in hydrogen-bonding interactions in (I) and (II) were located by difference methods and their positional and isotropic displacement parameters were refined. However, with (II), because of the poor reflections/refined parameters ratio, the parameters were fixed for the final refinement cycle. Other $\mathrm{H}$ atoms for both (I) and (II) were included at calculated positions (aromatic $\mathrm{C}-\mathrm{H}=0.95 \AA$ and aliphatic $\mathrm{C}-\mathrm{H}=0.97$ or $0.98 \AA$ ) and treated as riding $\left[U_{\text {iso }}(\mathrm{H})=1.2 U_{\text {eq }}(\mathrm{C})\right]$. Friedel pairs were averaged for the data used in the refinements. The absolute configuration determined for the parent L-(+)-tartaric acid, viz. 2R,3R (Waser, 1949; Bijvoet et al., 1951; Hope \& de la Camp, 1972), was invoked in both structures.

For both compounds, data collection: SMART (Bruker, 2000); cell refinement: SMART; data reduction: SAINT (Bruker, 1999); program(s) used to solve structure: SHELXS97 (Sheldrick, 1997) in WinGX (Farrugia, 1999); program(s) used to refine structure: SHELXL97 (Sheldrick, 1997) in WinGX; molecular graphics: PLATON (Spek, 2003); software used to prepare material for publication: PLATON.

The authors acknowledge financial support from the School of Physical and Chemical Sciences (Queensland University of Technology), the School of Science, Griffith University, and the School of Chemistry, The University of Melbourne.

Supplementary data for this paper are available from the IUCr electronic archives (Reference: SF3023). Services for accessing these data are described at the back of the journal.

\section{References}

Aakeröy, C. B. \& Hitchcock, P. B. (1994). Acta Cryst. C50, 759-761.

Aakeröy, C. B., Hitchcock, P. B. \& Seddon, K. R. (1992). J. Chem. Soc. Chem. Commun. pp. 553-555.

Albertsson, J., Oskarsson, ̊̊. \& Ståhl, K. (1979). J. Appl. Cryst. 12, 537-544.

Bijvoet, J. M., Peerdeman, A. F. \& van Bommel, A. J. (1951). Nature (London), 168, 271-272.

Bruker (1999). SADABS and SAINT (Version 6.02). Bruker AXS Inc., Madison, Wisconsin, USA.

Bruker (2000). SMART. Version 5.55. Bruker AXS Inc., Madison, Wisconsin, USA.

Bye, E. (1975). Acta Chem. Scand. Ser. B, 29, 22-28.

Carlström, D. (1973). Acta Cryst. B29, 161-167.
Debrus, S., Marchewska, M. K., Baran, J., Drozd, M., Pietraszko, A. \& Ratajczak, H. (2005). J. Solid State Chem. 178, 2880-2896.

Dobrzyńska, D. \& Jerzykiewicz, L. B. (2004). J. Chem. Crystallogr. 34, 51-55.

Etter, M. C. (1991). J. Phys. Chem. 95, 4601-4610.

Farrugia, L. J. (1999). J. Chem. Crystallogr. 32, 837-838.

Flack, H. D. (1983). Acta Cryst. A39, 876-881.

Fuller, J., Carlin, R. T., Simpson, L. J. \& Furtak, T. E. (1995). Chem. Mater. 7, 909-915.

Furuya, T., Fujita, S. \& Fujikura, T. (1989). Anal. Sci. 5, 489-490.

Glaser, R., Adin, I., Drouin, M. \& Michel, A. (1994). Struct. Chem. 5, 197-203. Główka, M. L. \& Codding, P. W. (1989). Acta Cryst. C45, 902-906.

Gould, R. O., Taylor, P., Walkinshaw, M. D. \& Bruins Slot, H. J. (1987). Acta Cryst. C43, 2405-2410.

Hope, H. \& de la Camp, U. (1972). Acta Cryst. A28, 201-207.

Johnson, M. N. \& Feeder, N. (2004a). Acta Cryst. E60, o1273-o1274.

Johnson, M. N. \& Feeder, N. (2004b). Acta Cryst. E60, o1374-o1375.

Johnson, M. N. \& Feeder, N. (2004c). Acta Cryst. E60, o1476-o1477.

Kania, I., Stadnika, K. \& Oleksin, B. J. (2004). Chirality, 16, 180-189.

Košutić-Hulita, N. \& Žegarac, M. (2005). Acta Cryst. C61, o171-o173.

Luner, P. E., Patel, A. D. \& Swenson, D. C. (2002). Acta Cryst. C58, o333-o335.

Manivannan, S., Dhanuskodi, S., Kirchbaum, K. \& Tiwari, S. K. (2006). Cryst. Growth Des. 6, 1285-1290.

Marchewska, M. K., Debrus, S., Pietraszko, A., Barnes, A. J. \& Ratajczak, H. (2003). J. Mol. Struct. 656, 265-273.

Okaya, Y., Stemple, N. R. \& Kay, M. I. (1966). Acta Cryst. 21, 237-243.

Puliti, R., Mattia, C. A., De Fazio, A., Ghiara, M. R. \& Mazzarella, L. (2001). Acta Cryst. C57, 1447-1449.

Rajagopal, K., Krishnakumar, R. V., Subha Nandhini, M. \& Natarajan, S. (2003). Acta Cryst. E59, o955-o958.

Rajagopal, K., Subha Nandhini, M., Krishnakumar, R. V. \& Natarajan, S. (2002). Acta Cryst. E58, o1306-01308.

Ryttersgaard, C. \& Larsen, S. (2003). Acta Cryst. E59, o1715-o1716.

Ryttersgaard, C. \& Larsen, S. (2004). Acta Cryst. E60, o4-o5.

Schjelderup, L., Groth, P. A. \& Aasen, A. J. (1990). Acta Chem. Scand. 44, 284 287.

Sheldrick, G. M. (1997). SHELXL97 and SHELXS97. University of Göttingen, Germany.

Smith, G., Wermuth, U. D., Healy, P. C. \& White, J. M. (2006). Unpublished data.

Smith, G., Wermuth, U. D. \& White, J. M. (2004). Acta Cryst. C60, o575-o581. Smith, G., Wermuth, U. D. \& White, J. M. (2006). Acta Cryst. C62, o353-o357. Spek, A. L. (2003). J. Appl. Cryst. 36, 7-13.

Stern, F. \& Beevers, C. A. (1950). Acta Cryst. 3, 341-346.

Subha Nandhini, M., Krishnakumar, R. V. \& Natarajan, S. (2001). Acta Cryst. C57, 423-424.

Wang, Z.-L., Li, M.-X., Wei, L.-H. \& Wang, J.-P. (2006). Acta Cryst. E62, o2508-02509.

Waser, J. (1949). J. Chem. Phys. 17, 498-499.

Zhang, H., Lin, Z.-Y., Zhou, Z.-H. \& Ng, S. W. (2003). Acta Cryst. E59, o1830185 . 